\title{
Should incomplete papers be published?
}

I wish to thank Dr. T. C. Huang, Editor in Chief, for encouraging the writing of this editorial. Its intent is to both alert readers to deficiencies prevalent in "much" of the current X-ray analysis literature [X-ray diffraction (XRD) and $\mathrm{X}$-ray fluorescence (XRF), and others]; and encourage readers to communicate a concern about these deficiencies to the editors. At one point I hesitated to use the word "much," so before using the word I decided to review at least 20 papers which described XRD experiments in recent X-ray analysis literature. After completing this exercise I was no longer hesitant to use the word because in reviewing the papers I found more than $50 \%$ of the papers lacked the critical information described below.

The critical information referred to is: a detailed description of how the specimen was prepared before inserting it into the specimen holder; and definition of every symbol in an equation, as well as the designation of the units of every constant or variable in the equation. Is it not true that completeness exists only if the contents of a paper provide the data mandatory for duplicating the experiment? There are, of course, always some exceptions such as those cases where proprietary information has to be omitted. In such a case, it would be helpful if the author included a statement to this effect.

Let us consider an example of an incomplete description of a procedure for preparing a specimen for an XRD analysis. If an author describes the method of preparing a specimen by simply stating that the sample (a portion of a rock) was ground in a mortar, is that satisfactory? Is this amount of information all that is needed for duplicating the experiment? Or, should there be information about the particle size attained? Pressure placed on the powder when placing it into the specimen holder? The kind of mortar? How long was the rock ground, etc.? Admittedly there may be instances when a sample cannot be treated prior to insertion in the analytical instrument specimen holder. However, when this restriction exists, should it not be so stated in the paper?

When an equation appears in an article, is it acceptable to simply give the equation and not define each symbol and state the units for each? Is it acceptable to assume that every reader already knows the units and definitions of the symbols? Does this satisfy the needs of the beginner?

If you are still skeptical that authors fail to include the items mentioned above, you may wish to examine any 20 recent papers containing equations, or which require the preparation of a specimen for an XRD or XRF analysis? After reading these papers, ask yourself if a reader can use the paper and obtain results which duplicate those described, using only the data given in the publication. Can the reader (in some cases a beginner) make a meaningful calculation from the data without knowing the units and definition of every symbol in the equation?

Editors of scientific journals share the responsibility with authors of publishing only complete articles. Editors have the tools to monitor the quality of a publication, namely, they have the delegated authority to obviate any such transgressions by simply refusing to publish any paper failing to meet the standard of completeness. It is unfortunately true that an examination of the literature will attest that a laxity of discipline to write a complete paper occurs too frequently.

Victor E. Buhrke

Portola Valley, California

And a note from the editor:

Dr. Buhrke received his Ph.D. in Analytical-Physical Chemistry from the University of Illinois, in Urbana, Illinois, in June of 1954. His research director was Professor G. L. Clark. After spending two years in the US Army Dr. Buhrke joined the Polychemicals Department of the DuPont company in Wilmington Delaware. His work at DuPont entailed the study of polymers by means of conventional X-ray Diffraction methods and by Small Angle Scattering. He also was the supervisor of the wet chemical laboratory for the division. He developed some non-aqueous titration methods for use in some of the DuPont plants. He later joined RCA to run the Applications Laboratories for the RCA electron microscope, and designed and ran the first Siemens Application laboratory (RCA was the distributor of Siemens X-ray equipment in the United States). Dr. Buhrke left RCA to become the Chief Engineer responsible for the design of Picker's X-ray diffraction equipment: which included the Picker Single Crystal Goniometer. He later became the Manager of the Picker Nuclear Medicine and Analytical Instrument Division, worldwide. He is the co-author and editor of a book on Specimen Preparation for X-ray Diffraction and X-ray Fluorescence; a member of the Denver X-ray Conference; has been the chairman of a workshop on specimen preparation, at the Denver X-ray Conference for over 20 years; is a member of the Steering Committee for the IXAS; or the board of directors of Rigaku USA, Inc.; a consultant to Rigaku; has presented papers at various meetings; and founded and ran his own business for over 30 years.

Ting C. Huang Editor-in-Chief 